\title{
ASSESSMENT OF PROCUREMENT METHODS USED FOR EXECUTING MAINTENANCE WORKS IN LAGOS STATE
}

\author{
ADENUGA, 0.A. ${ }^{1}$ and DOSUMU, 0.S. ${ }^{2}$ \\ http://dx.doi.org/10.4314/ejesm.v5i4.S6
}

\begin{abstract}
Received 16th August 2012; accepted 8th October 2012

The objectives of the study are to determine the procurement methods used by clients to execute maintenance works in Lagos state, identify the factors that influence the choice of those methods and establish the differences in the efficiencies of out-sourced and in-sourced maintenance. Out of the 60 questionnaires sent out to respondents, 34 (giving a response rate of 57\%) were retrieved and used for the study. The 34 responses were obtained from randomly selected organizations like Local Authority Housing, Housing Association, Residential Managing Agent, Universities, Health Authorities and Private Commercial Property Owners. The results of the study show that direct labour, lump sum contract and traditional contract, cost reimbursement contract and measured term contracts, are the most commonly adopted procurement methods in Lagos state for maintenance works. Time duration, cost of project and quality level required, are the major factors influencing the choice of procurement methods. Others are risk allocation, price competition and flexibility of contract. Finally, better access to special skills, getting the latest technologies, higher quality work and higher security are the important efficiency factors for out-sourcing and in-sourcing.
\end{abstract}

Key words: In-sourcing, Lagos state, Maintenance works, Out-sourcing, Procurement

\section{Introduction}

Maintenance procurement is the process by which required maintenance works are carried out, Wordsworth (2001). It is quite a different aspect because the infrastructure is already in place, but it needs to be maintained properly and rehabilitation and/or improvements need to be provided before any major deformation or deterioration that affect safe usage occurs. Oyegoke (2004) define procurement as the overall method used by a client/or representatives so as to arrive at a tender figure and other operation towards the selection of a contractor to deliver a project at an agreed time and conditions. According to Ogunsanmi (2001), the procurement process is also concerned with the form of procurement whether by contract or direct labour, and with the quality of delivery of both the work carried out and the level of service provided.

Procurement in the context of property development, regeneration and maintenance services, is the activity by which a housing association obtains its buildings and properties taking account of price, quality, time and sustainability to deliver overall best value, (Trimmer and Kidston, 2003). Masterman (2002) categorized procurement systems as separated, integrated, management oriented and discretionary method of procurement. The discretionary procurement method is divided into partnering and British Property Federations System. The integrated system is divided into design and build and its variants while the management oriented system is divided into construction management, management contracting and design and manage. There are different types of procurement methods in use for maintenance work and these include traditional contract, package deals, measured term contracting, prime contracting and construction partnering. In the construction of new buildings there are several methods of procurement which include the design and build, build own operate transfer, labour only, direct labour, construction management and the traditional system.

The maintenance of buildings is a complex and varied sector of the construction industry, accounting for approximately 5\% of the Gross Domestic Product in the United Kingdom (Wordsworth, 2001). The types of maintenance adopted and their implementation require careful consideration to ensure that both time and money are utilised efficiently (O'Reilly and Proverbs, 2008). Also, in maintenance works, the interaction 
between the form of procurement and the quality of the delivery are complex. Whereas in new build, the procurement process is essentially a matter of supplying products and labour to provide a finished building over a certain timescale, in maintenance the process involves liaising with and working around building users, in circumstances in which the works cannot be specified with certainty (Ogunsanmi and Bamisile 1997). The building size and the nature of the client have a great influence on maintenance procurement. According to British Standard Institution 3811 (1984) maintenance is defined as the combination of all technical and administrative actions including supervision, intended to retain an item, or restore it, to a state in which it can perform a required function. The maintenance of buildings have been a subject matter that has been long neglected and taken for granted within the construction industry in Nigeria and this can be attributed to the fact that "one of our greatest economic and social problems as a nation is the general absence of a maintenance culture.”(Adenuga, 2005). From previous research work carried out by Adebayo, 1999; Zubair, 1999; Oladapo, 2005 and Adenuga, 2008, maintenance of a building should not be after it has been erected or built but it should start from the inception of a building project that is the design stage to its completion. Construction of new projects is important but maintaining them thereafter is equally, if not more, important as a country that goes on building new structures but fails to effectively manage them burns its wealth and resources in a furnace" (Adenuga, 2005).

\section{The statement of the problem}

Building maintenance is a key factor in the construction industry contributing to overall client satisfaction and project success and the procurement of these services are to be critically assessed. It has been observed that our buildings suffer from rapid deterioration, dilapidation and decay and in order to save the buildings from being totally destroyed, there has to be proper maintenance work carried out on them. The problem, nevertheless, lies in the fact that there has been limited empirical research in this field of study. Procurement method from its selection continues to be topical, and several advanced studies have been reported. One of the key concerns of maintenance procurement is how to enhance objectivity with the input of industrial experts, critical procurement selection criteria and procurement strategies commonly used in Nigeria. Another problem lies within the fact that some studies about procurement methods is limited to amiably determine success factors that bring in benefit options for the organization. Thus, there lack of assessment tools that implies to research methods and materials to use in finding research evidences and support. While considerable research has been carried out on factors responsible for the poor maintenance of housing estates, offices and public buildings in Nigeria but only scant attention has been given to the key parameters in the procurement of maintenance works. There is therefore a need to establish and evaluate the procurement routes available for maintenance works using appropriate analysis.

\section{Aims and Objectives}

This research aims at assessing the procurement methods used for maintenance works in Lagos State, Nigeria.

The major objectives of this study are;

- To examine the procurement methods for maintenance work being adopted in Lagos state.

- To identify the factor(s) influencing the choice of procurement method in the delivery of maintenance work.

- To find out if there are variations in the maintenance efficiency based on the procurement methods applied.

\section{Methodology}

The subjects of this study were the experienced clients, consultants, maintenance managers and employees of the building construction industry in Lagos state, Nigeria. The techniques used are both qualitative and quantitative so as to yield large volumes of rich data from people. The random sampling technique was adopted for the selection of the sample size.

The questionnaires were administered on 60 maintenance service companies and consultants and 34 responses were received giving a response rate of $57 \%$. Responses came from Local Authority Housing, Housing Associations, Residential Managing Agents, Universities, Health Authorities and Private Commercial Property Owners. Data obtained through the questionnaires were tabulated and frequencies/percentages of 
responses to each of the questions asked were analysed using the Statistical Package for Social Sciences (SPSS 16) software.

\section{Results}

Table 1 shows the socio-economic characteristics of the respondents used for this study. The characteristics include their places of work, years of experience and number of employees in their organisation.

Table 1 Socio-Economic Characteristics of Respondent

\begin{tabular}{lll}
\hline & Frequency & Percentage (\%) \\
\hline Place of work & & \\
Local Housing Authority & 3 & 9 \\
Housing Association & 3 & 9 \\
Residential Managing Agent & 10 & 6 \\
Universities & 2 & 12 \\
Health Authorities & 4 & 32 \\
Private Commercial & 11 & 3 \\
Others & 1 & $\mathbf{1 0 0}$ \\
Total & $\mathbf{3 4}$ & \\
Years of experience & & 85 \\
Less than 10 years & 29 & 15 \\
$10-19$ years & 5 & 0 \\
$20-29$ years & 0 & 0 \\
30 years and above & 0 & $\mathbf{1 0 0}$ \\
Total & $\mathbf{3 4}$ & \\
Number of employees & & 46 \\
$1-10$ & 15 & 12 \\
$11-30$ & 4 & 9 \\
$61-100$ & 3 & 30 \\
$101-500$ & 10 & 3 \\
Above 500 & 1 & $\mathbf{1 0 0}$ \\
Total & $\mathbf{3 3}$ & \\
& &
\end{tabular}

Residential Managing Agents and Private Commercial property owners (such as Banks, Construction Industries, and Hotels) top the list with respective percentages of 29 and 32 respectively. These represent a combined proportion of $61 \%$. Local Authority Housing (such as LSDPC) and Housing Associations both constitute $9 \%$ each of the respondents. Universities represent 6\% and Health Authorities represent $12 \%$. Also, majority of the respondents
(85\%) have worked for less than 10 years while the rest (15\%) of them have worked for 10- 19 yrs. Most (64\%) of the respondents were from organisations having between 1-10 employees, followed by $30 \%$ which were from organisations with between101- 500 employees, while another 9\% have 61- 100 employees, $12 \%$ have between 11- 30 employees and 3\% have employees of above 500 . 


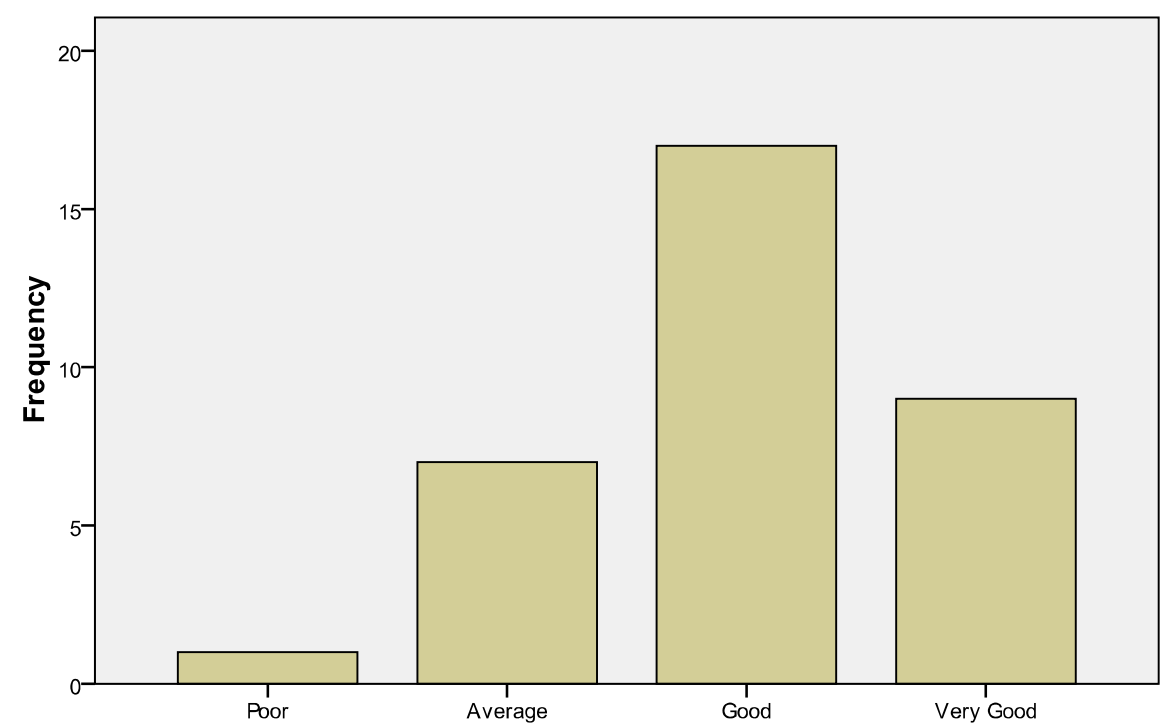

Figure 4 Conditions of housing stock managed by firms

Figure 4 shows the overall condition of the housing stock managed or owned by respondents. $50 \%$ of the respondents claimed that their building stocks were in good condition, another $27 \%$ stated that their buildings were in very good condition while $21 \%$ noted that their building conditions were average and $1 \%$ had their buildings in poor condition.

Table 2 Maintenance Procurement Methods used by clients

\begin{tabular}{lccc}
\hline Maintenance Procurement Methods & Frequency & Percentage (\%) & Rank \\
\hline Direct Labour & 25 & 74 & 1 \\
\hline Lump Sum Contracts & 17 & 50 & 2 \\
Traditional Contract & 16 & 47 & 3 \\
Cost Reimbursement Contracts & 12 & 36 & 4 \\
Measured Term Contracts & 10 & 30 & 5 \\
Design and Build & 7 & 21 & 6 \\
Service Level Agreements & 6 & 18 & 7 \\
Term Contracts & 5 & 15 & 8 \\
Dayworks & 4 & 12 & 9 \\
Package Deals & 2 & 6 & 10 \\
Fixed Price Contracts & 2 & 6 & 11 \\
Open Orders & 2 & 6 & 12 \\
Partnering & --- & --- & 13 \\
Management Routes & --- & --- & 14 \\
Prime Contracting & --- & --- & 15 \\
Others & --- & --- & 16 \\
\hline
\end{tabular}

Table 2 shows the order of use of the maintenance procurement methods adopted in Lagos state, Nigeria. The direct labour (74\%), lump sum contract (50\%), traditional contract (47\%) and cost reimbursement contracts (36\%) were the mostly used among the procurement methods. Other methods used are measured term contracts $(30 \%)$, design and build (21\%), service level agreement (18\%), term contracts (15\%), day works (12\%), open orders (6\%), fixed price contract (6\%) and package deal (6\%). Management routes, 
prime contracting and partnering methods of procurement were never used for maintenance procurement in Lagos state.

Table 3 Contractor Selection Criteria

\begin{tabular}{lcc}
\hline Contractor Selection Criteria & Frequency & Percentage (\%) \\
\hline Open competitive bidding & 11 & 32 \\
Selective tendering & 8 & 24 \\
Negotiation & 23 & 68 \\
Others & 4 & 12 \\
\hline
\end{tabular}

Table 3 shows that majority (68\%) of the respondents use Negotiation as a means of contractor selection. Open competitive bidding (32\%) and selective tendering (24\%) and other criteria (12\%) not mentioned in this list were also used as criteria for contractor selection in some cases.

Table 4 Basis of Contractor Award

\begin{tabular}{lcc}
\hline Basis of Contractor Award & Frequency & Percentage (\%) \\
\hline Bills of Quantities & 22 & 65 \\
Cost Reimbursement & 4 & 12 \\
Schedule of Rates & 7 & 21 \\
Others & 3 & 9 \\
\hline
\end{tabular}

Table 4 indicates that most (65\%) of the maintenance works are awarded based on bills of quantities in Lagos state, $12 \%$ were based on cost reimbursement, $21 \%$ were based on schedule of rates and $9 \%$ were based on other documents. This shows that the bills of quantities and schedule of rates were the most favoured basis for maintenance contract awards in Lagos state.

Table 5 Factors influencing the choice of maintenance procurement methods

\begin{tabular}{llc}
\hline Factor & Mean & Rank \\
\hline Time certainty & 4.7 & 1 \\
Price certainty & 4.6 & 2 \\
Quality level & 4.6 & 3 \\
Responsibility & 4.5 & 4 \\
Speed & 4.2 & 5 \\
Risk allocation & 4.2 & 6 \\
Price competition & 4.2 & 7 \\
Others & 4.0 & 8 \\
Flexibility & 3.8 & 9 \\
Complexity & 3.6 & 10 \\
\hline
\end{tabular}

1 Not Important $\mathbf{2}$ of little importance $\mathbf{3}$ somewhat importance $\mathbf{4}$ important, $\mathbf{5}$ Very important.

Table 5 shows the mean scores of the factors used by clients to determine the procurement methods to be used for the maintenance of their buildings. Time certainty (4.7), price certainty (4.6) and quality level (4.6) are the main factors used by clients to determine the procurement methods to be used for 
maintenance works. Other factors considered are responsibility (4.5), speed (4.2), risk allocation (4.2), price competition (4.2) and other criteria (4.0) that are not included in the study.

Table 6 Importance of maintenance operation under outsourcing and in-sourcing services

\begin{tabular}{lcccl}
\hline Efficiency of Maintenance Operations & $\begin{array}{c}\text { Outsourcing } \\
\text { Mean }\end{array}$ & Rank & $\begin{array}{c}\text { In-sourcing } \\
\text { Mean }\end{array}$ & Rank \\
\hline Better access to special skills & 4.4 & 1 & 4.4 & 1 \\
\hline Get the latest technologies & 4.4 & 2 & 4.4 & 2 \\
Higher quality work & 4.3 & 3 & 4.3 & 3 \\
Higher security & 4.3 & 4 & 4.3 & 4 \\
Minimize equipment downtime & 4.2 & 5 & 4.2 & 5 \\
Better adjustment to workload & 4.1 & 6 & 4.1 & 7 \\
fluctuations & & & & \\
Avoiding penalties for delay & 4.0 & 7 & 4.0 & 8 \\
Better control of services & 3.9 & 8 & 3.9 & 9 \\
More flexibility in staffing & 3.8 & 9 & 3.8 & 10 \\
Reduced equipment expenditures & 3.7 & 10 & 3.7 & 11 \\
Specialized expertise & 3.7 & 11 & 3.7 & 12 \\
Reduced cost & 3.6 & 12 & 4.2 & 6 \\
\hline
\end{tabular}

1 Not important 2 of little Importance 3 Somewhat Important, 4 Important, 5 Very Important

Table 7 indicates that better access to special skills, get the latest technologies, higher quality work, higher security and minimize equipment downtime were important to both out-sourcing and in-sourcing. The factors rated first to fifth accordingly. Other factors were equally important as shown in the table but while reduced cost rated $6^{\text {th }}$ for in-sourcing, it rated $12^{\text {th }}$ for out-sourcing. Specialized expertise, reduced equipment expenditure and more flexibility in staffing were rated very low for both out-sourcing and insourcing. On the overall, it can be concluded that the same factors were important for both out-sourcing and in-sourcing.

\section{Discussion}

In the choice of procurement methods used for maintenance works in Lagos State, the predominant methods adopted amongst others are direct labour, lump sum contract and traditional contract. The factors influencing the choice of these procurement methods in the delivery of maintenance works are duration of project (time), the cost of the project, quality level, risk allocation, price competition and flexibility. These findings are to some extent similar to Oyegoke (2004), Ogunsanmi (2001) and Ogunsanmi and Bamisile (1997). In their survey of procurement methods, duration of the project, total cost of the project, quality according to specifications were ranked as the most influential factor in the choice of procurement methods, attributable to the volume of work to be maintained.

In the three studies, negotiation was ranked as the most predominant method of selecting contractor for maintenance work. Also, from this study, negotiation was rated as the most frequently used followed by selective tendering and open competitive bidding. Bills of quantities was rated as the most frequently used for awarding contract followed by schedule of rates and cost reimbursement.

In prioritizing the efficiency of maintenance services for outsourcing services the top 12 reasons were ranked accordingly as follows; better access to special skills, get the latest technologies, higher quality work, higher security, better adjustment to workload fluctuations, avoiding penalties for delay, better control of services, more flexibility in staffing, reduced equipment expenditures, specialized expertise and reduced cost. And in prioritizing the efficiency of maintenance services for in-sourcing services the top 12 reasons were ranked in order of importance as follows; better access to special skills, get the 
latest technologies, higher quality work, higher security, reduced cost, minimize equipment downtime, better adjustment to workload fluctuations, avoiding penalties for delay, better control of services, more flexibility in staffing, reduced equipment expenditures and specialized expertise.

\section{Conclusion}

This research work has helped to assess the procurement methods used for maintenance works and has been able to identify the most commonly used methods for procuring such works. It has also identified the main procurement selection criteria for deciding the appropriate method of procurement. However, it should be noted that this study, like most research work, was conducted on a segment of the population and the extent to which the result is representative of the entire population is definitely not absolute.

The factors that influence the choice of maintenance procurement methods have been identified and they need to be borne in mind so that the wrong method would not be used to procure maintenance works.

\section{Reference}

Adebayo, S.O. (1991), A study of the maintenance management of public buildings in Nigeria. Unpublished Ph.D. thesis, Dept. of Building, University of Lagos, Lagos, Nigeria.

Adenuga,O.A. (2005), "Building maintenance in Nigeria: Structural Deterioration, Recognition Diagnosis of Causes and Remedies", Shelter Watch 2 (01), 5-25.

Adenuga (2008), Evaluation of maintenance management of public hospital buildings in South West, Nigeria, Unpublished Ph.D. thesis, Dept. of Building, University of Lagos, Lagos, Nigeria.

British Standards, Institution (1984), B.S 3811: Glossary of general terms used in maintenance organization. BSI, London.
Masterman, J. W. E. (2002), An Introduction to Building Procurement Systems. 2nd Ed., London; New York: Spon Press.

Ogunsanmi O.E. (2001), A comparative study of the performance of traditional and labour- only procurements in some selected states in Nigeria. Unpublished Ph.D thesis, department of building, University of Lagos, Akoka, Lagos, Nigeria.

Ogunsanmi O.E.and Bamisile, A. (1997), Factors affecting the selection of project procurement methods. Builders' Magazine 7 (2) 9-13.

Oladapo, Y. (2004), Evaluation of the maintenance management of the staff housing estates of selected first generation Universities in South-West, Nigeria. Unpublished Ph.D. thesis, Dept. of Building, Obafemi Awolowo, University, Ile - Ife, Osun State, Nigeria.

O'Reilly, and Proverbs, D.G. (2008), 'Customer Satisfaction and Service Delivery in the Maintenance Department of UK Local Authorities: Results of a Case Study', The Construction and Building Research Conference of the Royal Institution of Chartered Surveyors (COBRA), Dublin Institute of Technology.

Oyegoke, A. S. (2001), UK and US Construction management contracting procedures and practices: a comparative study. Journal of Construction Engineering and Architectural Management, 8 (5/6) 403-417.

Trimmer, and Kidston, N. (2003), Assessing procurement, Trimmer CS and The Housing Corporation, London.

Wordsworth, P. (2001), Lee's Building Maintenance Management. 4th Ed., Oxford: Blackwell Science.

Zubairu, S. N. (1999), Maintenance of government office buildings in Nigeria - a post occupancy evaluation approach. Unpublished Ph.D. thesis, Department of Building, University of Lagos, Lagos, Nigeria. 